\title{
Olhares epistemológicos e a pesquisa educacional na formação de professores de ciências
}

\author{
Alberes de Siqueira Cavalcanti
}

\section{Resumo}

Não existe professor de ciências sem uma epistemologia de fundo, sem uma base epistemológica que dê sustentação para o seu trabalho pedagógico. Não há pesquisa propriamente dita sem uma base epistemológica. Assim, para se formar o professor pesquisador, há que se enfrentar o desafio da formação epistemológica e a consequente discussão sobre os olhares epistemológicos. 0 objetivo do artigo é apresentar algumas das principais abordagens epistemológicas no campo da pesquisa em educação: dialética, positivismo, fenomenologia, estruturalismo e complexidade. A partir da metáfora do olhar, na relação sujeito-objeto do conhecimento, as epistemologias são discutidas enquanto possibilidades de olhares diversos sobre os fenômenos educacionais; ora convergentes, ora divergentes, completando-se ou excluindo-se. 0 que um olhar epistemológico enxerga outro pode não enxergar. Estaremos, nessa ótica da pesquisa educacional, numa dinâmica constante entre visão e/ou cegueira, a possibilidade de lucidez e/ou obscuridade. A Dialética representa o olhar em movimento, buscando captar o objeto na sua totalidade, desde uma perspectiva histórica de mudanças e contradições. 0 Positivismo representa o olhar de fora que se distancia buscando quantificar e mensurar o objeto, tornando-o imune à subjetividade daquele que o descreve. A Fenomenologia representa o olhar de dentro, do que é vivenciado e interpretado por sujeitos em determinado momento. 0 Estruturalismo representa o olhar por baixo que busca captar o que dá sustentação, a estrutura dos fenômenos sociais independente dos seus condicionamentos históricos. A Complexidade representa o olhar multidimensional que busca compreender a realidade no tecido complexus, em conjunto, considerando a incerteza e a incompletude.

\section{Palavras-chave}

I- Instituto Federal de Educação do Maranhão, Epistemologia - Pesquisa educacional - Formação de professores. São Luís Monte Castelo, MA, Brasil.

Contato: alberes@ifma.edu.br 


\title{
Epistemological views and educational research in the science teacher education
}

Alberes de Siqueira Cavalcantil

\begin{abstract}
There are no science teachers without a background epistemology, without an epistemological basis that gives them support for their teaching job. There is no research without an epistemological basis. Thus, to train research teachers, there is a need to face the challenge of epistemological training and the consequent discussion about epistemological views. The objective of this article is to present some of the main epistemological approaches in the field of educational research: dialectics, positivism, phenomenology, structuralism and complexity. Using the metaphor of vision in the subject-object relation of knowledge, I discuss epistemologies as possibilities of different views of the educational phenomena, which are sometimes convergent, sometimes divergent, complementing or excluding themselves. What an epistemological vision sees the other cannot see. In this perspective of educational research, we will be in constant dynamics between vision and/or blindness, the possibility of clarity and/or obscurity. Dialectics represents the vision in motion, seeking to capture the object in its entirety, from a historical perspective of changes and contradictions. Positivism is the outside vision, which distances itself seeking to quantify and measure the object, making it immune to the subjectivity of those who describe it. Phenomenology is the vision from inside, from what is experienced and interpreted by subjects at a given moment. Structuralism is the vision from underneath, which seeks to capture what sustains, the structure of social phenomena, regardless of their historical conditions. Complexity is the multidimensional vision that seeks to understand the complex fabric of reality, together, considering uncertainty and incompleteness.
\end{abstract}

\section{Keywords}

Epistemology - Educational research - Teacher education.

I- Instituto Federal de Educação do Maranhão, São Luís Monte Castelo, MA, Brasil.

Contato: alberes@ifma.edu.br 


\section{Introdução}

Tanto as discussões atuais no campo acadêmico como a legislação referente à formação docente tendem a apresentar um modelo de formação interdisciplinar ou transdisciplinar, que rompa com um modelo disciplinar fechado e fragmentado e possibilite ao professor uma visão mais aberta, crítica e relacional da sua área de conhecimento com os demais saberes e da própria reformulação da concepção de ciência. No entanto, ainda é possível observar nos cursos de licenciatura a persistência de uma perspectiva reducionista de formação docente, que tende a reproduzir eufemisticamente uma formação bacharelesca, com um verniz de licenciatura. Tal perspectiva reducionista leva a considerar o ensino como a transmissão de conteúdos de áreas específicas (física, química, biologia...). Por essa ótica, um bom professor será formado para dominar e transmitir o conteúdo de sua área.

No contexto atual de crise da razão e mudanças paradigmáticas, a formação docente não pode mais contentar-se com uma perspectiva reducionista. No bojo dessas mudanças repercutidas na educação em ciências, alguns estudos vêm demonstrando de forma consensual a relevância da epistemologia na formação e no exercício profissional dos professores de ciências (PORLÁN; GARCÍA; POZO, 1998; PRAIA; CACHAPUZ; GIL-PÉREZ, 2002). A formação acadêmica e a produção do conhecimento científico pressupõem a pesquisa, que por sua vez envolve a questão epistemológica, ou seja, como apreendermos o real. Em termos de produção de conhecimento filosófico ou científico, não nos é possível iniciar e levar a cabo tal produção sem o aporte epistemológico e metodológico:

A falta da formação filosófica reduz a problemática da pesquisa científica a uma simples questão de opções técnicas relacionadas à seleção de alguns encaminhamentos, fórmulas ou receitas, apresentados nos tradicionais manuais de pesquisa. Esses "reducionismos" poderão ser superados intensificando a formação filosófica dos educadores e principalmente sua formação epistemológica. (GAMBOA, 2012, p. 105)

Sempre que estamos no campo da epistemologia, fazemos filosofia do conhecimento científico. Seja esta filosofia, reflexão ou teoria da ciência desenvolvida por filósofo ou cientista, não mudará a sua natureza filosófica, uma vez que as questões epistemológicas são questões filosóficas que permanecem em aberto.

0 texto nasceu de uma preocupação didática num contexto de ensino, da necessidade sentida em sala de aula de ter um recurso introdutório e didático que possibilitasse discutir com acadêmicos de licenciaturas a importância e o papel das epistemologias na formação de professores, especialmente dos professores de ciências. Nesse sentido, o texto é limitado em sua pretensão teórica, não podendo dar conta de questões epistemológicas outras (como a natureza da ciência, o ceticismo, o relativismo) que requerem uma discussão específica, pois envolvem conceitos complexos de verdade e de ciência, remontando a um longo percurso histórico e filosófico.

0 propósito do texto é apresentar, de forma introdutória e didática, algumas das principais abordagens epistemológicas no campo da educação (materialismo histórico dialético, positivismo, fenomenologia, estruturalismo e complexidade). A sua organização é feita de forma a oferecer uma compreensão conceitual e as categorias norteadoras de cada epistemologia e, por fim, buscar os elementos de procedimentos metodológicos para a pesquisa educacional. Cada uma dessas epistemologias é abordada a partir da metáfora do olhar, na relação entre sujeito e objeto do conhecimento.

Quando opto pela metáfora do olhar, tenho consciência da ruptura bachelardiana em relação à hegemonia da ocularidade na tradição filosófica ocidental. Nesse sentido, o 
conhecimento é entendido como uma extensão da visão. A ocularidade é um tema recorrente na tradição ocidental, que se observa pelo predomínio de expressões visuais como visão de mundo, cosmovisão, leitura de mundo, ponto de vista, evidência, foco, intuição, perspectiva, olhar, elucidação, etc., e no jogo metafórico da bipolaridade luz e trevas. 0 conhecimento é luz, a ignorância é trevas (tema que recorda, dentre outros: o mito de Prometeu, a gnosiologia platônica, a cegueira de Édipo, a razão iluminista, a ciência moderna). Também falamos de olhar filosófico, pisicológico, histórico ou visão da física, da antropologia etc. para designarmos o corte epistêmico em relação a um determinado estudo. Por ser uma imagem tão cara à tradição ocidental, penso que a metáfora da visão não pode ser tão facilmente descartada do nosso imaginário, embora reconheça que não pode ser a única e que a sua principal fraqueza é a possibilidade de uma interpretação equivocada do conhecimento como mera contemplação, em que o sujeito é mero espectador do mundo, recebendo passivamente as impressões do objeto.

Longe dessa interpretação objetivista, espetacular e de realismo ingênuo, observo que a metáfora da visão ganha novas cores com os recentes estudos ligados à neurociência. Meyer (2002) usa a expressão "visão pensante" ao recordar que os estudos psicológicos sobre a formação de uma imagem visual levam à constatação de que “a visão não é uma percepção que ocorre por inércia, uma recepção de objetos exteriores que se impõem em bloco a células visuais passivas e complacentes" (MEYER, 2002, p. 78). E mais:

Os objetos não nos são dados como tais, são reconhecidos e reconstruídos por um cérebro dotado de capacidades de análise, de sintese e de hierarquização. Não é $o$ olho, mas sim o cérebro que vê. (MEYER, 2002, p. 78, grifo meu)

Portanto, a metáfora da visão é aqui tomada não no sentido de uma simples contemplação da realidade, mas, ao contrário, para sublinhar o papel ativo que uma teoria/ epistemologia adotada pelo sujeito epistêmico desempenha na sua leitura de mundo e na construção do seu objeto de estudo.

\section{Epistemologia e formação docente}

Em outro trabalho (CAVALCANTI; SILVA; MACÊDO, 2013), constatamos uma tendência consensual de autores a estabeler uma relação direta, de causa e efeito, entre epistemologia e formação docente. Simplificando, poderíamos afirmar que uma boa e consistente formação epistemológica é um dos pilares para uma boa e consistente formação docente; o que equivale a dizer que a ausência ou o pouco investimento na formação epistemológica dos professores de ciências repercute negativamente no seu desempenho em sala de aula enquanto profissionais da educação (CAVALCANTI; SILVA; MACÊDO, 2013).

De acordo com Praia, Cachapuz e GilPérez (2012):

A epistemologia está necessariamente implícita em qualquer currículo de Ciências. É dela em boa parte a concepção de Ciência que é ensinada. É nossa convicção, pois, que o conhecimento de epistemologia torna os professores capazes de melhor compreender que Ciência estão a ensinar, ajuda-os na preparação e na orientação a dar às suas aulas e dá um significado mais claro e credível às suas propostas. Tal conhecimento ajuda, e também obriga os professores a explicitarem os seus pontos de vista, designadamente sobre quais as teses epistemológicas subjacentes à construção do conhecimento científico, sobre o papel da teoria, da sua relação com a observação, da hipótese, da experimentação, sobre o método, e ainda aspectos ligados à validade e legitimidade 
dos seus resultados, sobre o papel da comunidade científica e suas relações com a sociedade. [...] a epistemologia ajuda os professores a melhorarem as suas próprias concepções de ciência e a fundamentação da sua acção pedagógicodidáctica. (2002, p. 128).

No contexto contemporâneo, em que a ciência é posta em questão, não é possivel pensar a formação docente à margem das discussões epistemológicas. No paradigma científico da modernidade, a ciência é vista como um conhecimento racional, universal, que aspira à formulação de leis, à luz de regularidades observadas, com vistas a prever o comportamento futuro dos fenômenos. Daí o mundo mecanicista do racionalismo cartesiano e da mecânica newtoniana reduzindo a complexidade do mundo a leis simples de um conhecimento utilitário e funcional que aos poucos avançou de um estudo da natureza para o estudo da sociedade (CAVALCANTI; BRUSSIO, TOURINHO, 2006). Tal paradigma consolidou a imagem de ciência que ainda perdura na formação docente e na orientação de boa parte do ensino e das pesquisas realizadas pelos professores de ciências. Na crise paradigmática que vivenciamos, assistimos à emergência de novos olhares epistemológicos, que aos poucos passam a influenciar tanto a formação como a prática docente. Ter ciência desse campo de batalha epistemológico faz parte da agenda formativa dos professores.

Não existe professor de ciências sem uma epistemologia de fundo, sem uma base epistemológica que lhe dê sustentação para o seu trabalho pedagógico. Mesmo que essa epistemologia esteja subjacente, de forma implícita, inconsciente e acrítica, ela permanece orientando a prática docente. A ignorância ou o silêncio sobre as bases epistemológicas na formação dos professores é condição relevante para uma prática docente que fossiliza uma imagem distorcida da ciência, que corrobora para a manutenção do status quo (individualismo, neutralidade, dicotomia sujeito-objeto, verdade única e absoluta, elitismo) (CAVALCANTI; SILVA; MACÊDO, 2013).

Uma epistemologia, enquanto teoria do conhecimento científico, busca explicitar o processo de produção da ciência, fornecendo uma elucidação da natureza da ciência, o critério de cientificidade, a maneira de intelecção e explicação científica da realidade. É fundamental que, na formação docente, especialmente de professores de ciências, e na pesquisa educacional, a dimensão epistemológica esteja presente como um grande pano de fundo que perpassa e interliga educação e ciência, ensino e pesquisa.

A pesquisa educacional integra a formação e a profissionalidade docente, isto é, o professor forma-se pela pesquisa e pela pesquisa também exerce a docência. No entanto, não há pesquisa propriamente dita sem uma base epistemológica. Assim, para se formar o professor pesquisador, há que se enfrentar o desafio da formação epistemológica e a consequente discussão sobre os olhares epistemológicos.

\section{O olhar em movimento}

0 olhar em movimento é característico da dialética, é um olhar que busca captar o objeto na sua totalidade, desde uma perspectiva histórica de mudanças e contradições. Esse olhar foi introduzido na tradição filosófica ainda na antiguidade grega por Heráclito. Passou um longo tempo esquecido e, só a partir da filosofia de Hegel (1770-1831), a concepção dialética da realidade foi retomada na história do pensamento ocidental. Karl Marx (1818-1883) e Friedrich Engels (18201899) deram continuidade ao pensamento dialético, rompendo, contudo, com o idealismo hegeliano e concebendo a dialética com base no materialismo histórico. Do ponto de vista educacional, o materialismo histórico-dialético exerce forte influência, especialmente pelas contribuições filosóficas de Antonio Gramsci, o sociointeracionismo advindo de Lev Vygotsky, 
a releitura frankfurtiana do marxismo expressa na Teoria Crítica.

0 materialismo histórico-dialético defende a primazia da matéria sobre o espírito, opondo-se ao idealismo. A matéria é primária e é a fonte da consciência. Explica a história a partir dos fatores materiais (modo de produção), concebidos como processos dinâmicos da relação homem-natureza: "0 modo de produção da vida material condiciona o processo em geral de vida social, política e espiritual. Não é a consciência dos homens que determina o seu ser, mas, ao contrário, é o seu ser social que determina sua consciência” (MARX, 1999, p.52).

0 materialismo histórico-dialético é uma teoria e um método de explicação da realidade. Enquanto teoria, a dialética concebe a realidade como uma totalidade concreta, caracterizada pela contradição e o pelo movimento. Nesse sentido, não só o real é dialético, como também o próprio pensamento que busca conhecer o real comunga desse mesmo estatuto ontológico: "Se o real está em movimento, então que o nosso pensamento também se ponha em movimento e seja pensamento desse movimento. Se o real é contraditório, então que o pensamento seja pensamento consciente da contradição" (LEFEBVRE, 1979, p. 174).

Ao se afirmar que a dialética concebe o real como uma totalidade, deve-se evitar uma compreensão equivocada de tal afirmação. Segundo Kosik, a totalidade não deve ser compreendida como a soma de "todos os fatos", mas sim como um todo que possui a sua própria estrutura (não é caótico), que se desenvolve (não é imutável, nem dado de uma vez por todas) e que se vai criando (não é perfeito e acabado no seu conjunto):

A dialética da totalidade concreta não é um método que pretenda ingenuamente conhecer todos os aspectos da realidade, sem exceções, e oferecer um quadro "total" da realidade, na infinidade dos seus aspectos e propriedades; é uma teoria da realidade concreta e do conhecimento que dela se tem como realidade. A totalidade concreta não é um método para captar e exaurir todos os aspectos, caracteres, propriedades, relações e processos da realidade; é a teoria da realidade como totalidade concreta. (KOSIK, 1976, p. 36)

A categoria da totalidade, portanto, não é estática, fechada. A totalidade é movimento e relação. Tudo - os fenômenos, as coisas, o pensamento - está em movimento e em relação. 0 que faz o movimento é a contradição. E “a contradição dialética deve ser encarada como sintoma da realidade. Só é real aquilo que apresenta contradições, aquilo que se apresenta como unidade de contradições" (LEFEBVRE, 1979, p. 192).

Dessas considerações, resultam algumas implicações metodológicas para a pesquisa e a produção do conhecimento. Se quisermos realizar uma pesquisa a partir da dialética, teremos que considerar as "leis da dialética":

a) Lei da interação universal - o nosso objeto de pesquisa, o fenômeno por nós estudado, não poderá ser isolado, mas antes inserido numa totalidade da qual é parte. 0 nosso objeto deverá ser relacionado com outros fenômenos, para que possamos compreendê-lo e explicá-lo na sua totalidade.

b) Lei do movimento universal - o nosso objeto de pesquisa não poderá ser entendido nem explicado como algo estático, mas em movimento. Ele muda, se transforma internamente e é transformado externamente pelo movimento da totalidade da qual é um fenômeno.

c) Lei da unidade dos contraditórios o nosso objeto de pesquisa também possui suas contradições internas e elas devem ser percebidas pelo pesquisador, pois são elas que produzem o movimento que transforma o real.

d) Transformação da quantidade em qualidade - o nosso objeto de pesquisa não pode ser analisado separadamente em termos quantitativos

1-A nomenclatura e a sequência das leis da dialética segue a apresentação dada por Lefebvre (1979, p. 237-239), a partir da qual busco interpretá-las na perspectiva da realização de uma pesquisa em educação. 
ou qualitativos. Quantidade e qualidade estão dialeticamente em relação. Portanto, para analisar o fenômeno pesquisado, devemos estabelecer a relação quantidade e qualidade.

e) Lei do desenvolvimento em espiral o objeto por nós estudado deve ser tomado na continuidade do movimento da totalidade na qual está inserido. Ele pode ser uma superação de algo que o antecedeu, mas também pode ser superado. Mas o pesquisador deverá perceber que o passado e que a possibilidade do devir se encontram no fenômeno por ele estudado.

Podemos sinteticamente concluir o seguinte acerca da pesquisa que se proponha numa abordagem dialética: o seu objeto, seja ele qual for, deverá ser estudado na sua relação com a totalidade da qual é parte. 0 pesquisador dialético não isola o seu objeto do contexto maior no qual está inserido. Da mesma forma, o pesquisador dialético não se aproximará do seu objeto como se ele fosse estático. Ao contrário, o apreenderá nas suas contradições internas, percebendo o seu movimento e as possibilidades de mudança. Assim, o pesquisador dialético buscará conhecer para transformar o conhecido e, dialeticamente, ao fazer isso, também se transformará.

\section{O olhar de fora}

0 olhar que toma distância do seu objeto, o olhar de fora, é o olhar do positivismo. 0 positivista busca quantificar e mensurar o objeto, de tal forma que a sua descrição esteja imune da subjetividade daquele que o descreve. Esse olhar que pretende a objetividade e a neutralidade já era buscado nas filosofias modernas do empirismo (Bacon) e do racionalismo (Descartes). Coube a Augusto Comte (1798-1857) a elaboração de uma síntese entre empirismo e racionalismo, resultando no positivismo. Se Comte é considerado o grande idealizador do positivismo, Émile Durkheim (1855-1917) é por sua vez o teórico que forneceu as bases metodológicas para a produção do conhecimento na perspectiva positivista. 0 positivismo é caracterizado como uma corrente filosófica que defende o primado da ciência no conhecimento da realidade. Nessa corrente, toda a concepção da realidade, parte da adoção do método das ciências naturais como única possibilidade de conhecimento do real.

Partindo de uma concepção da "evolução intelectual da humanidade", Comte conclui que qualquer especulação que façamos sobre o "indivíduo" ou a "espécie" passará por três estados teóricos: o teológico, o metafísico e o positivo. No entanto, o estado positivo constitui o ápice da evolução humana, quando a humanidade atinge a sua maturidade e adquire a capacidade de conhecer efetivamente o real. Contrapondo-se à teologia e à metafísica, afirma que, no estado positivo,

[...] o espírito humano renuncia de vez às pesquisas absolutas, que só convinham à sua infância. Circunscreve seus esforços ao domínio, que agora progride rapidamente, da verdadeira observação, única base possível de conhecimentos verdadeiramente acessíveis, sabiamente adaptados a nossas necessidades reais. Reconhece de agora em diante, como regra fundamental, que toda proposição que não seja estritamente redutivel ao simples enunciado de um fato, particular ou geral, não pode oferecer nenhum sentido real $\mathrm{e}$ inteligível. A revolução fundamental, que caracteriza a virilidade de nossa inteligência, consiste essencialmente em substituir em toda parte a inacessível determinação das causas propriamente ditas pelas simples pesquisas das leis, isto é, relações constantes que existem entre os fenômenos observados. (COMTE, 1973, p. 55).

0 positivismo, enquanto uma teoria que busca explicar a realidade, tratará a realidade a partir dos fatos e, a exemplo das ciências naturais, buscará descobrir as leis necessárias e universais presentes nos fenômenos. Os fatos se apresentam para o positivismo dentro de uma realidade, de um todo, que observa uma ordem 
harmoniosa e um progresso que naturalmente segue um percurso evolutivo da história.

Sob essa ótica positivista, como podemos compreender a realização de pesquisa e a produção do conhecimento? Quem nos oferece os elementos para tal compreensão é Durkheim, através de As Regras do Método Sociológico ${ }^{2}$. Inicialmente, Durkheim apresenta a sua definição de fato social, a partir da qual é possível ter a clareza conceitual necessária para empreender o método:

É um fato social toda a maneira de fazer, fixada ou não, suscetível de exercer sobre o indivíduo uma coação exterior; ou ainda, que é geral no conjunto de uma dada sociedade tendo, ao mesmo tempo, uma existência própria, independente das suas manifestações individuais. (DURKHEIM, 1973, p. 394).

Desta definição decorrerá "a primeira regra e a mais fundamental", no dizer de Durkheim, que é "a de considerar os fatos sociais como coisas”. Esta regra terá três implicações para o pesquisador, como veremos adiante, mas basta o seu enunciado para percebermos o tipo de tratamento e postura que o pesquisador deverá adotar ante ao seu objeto de pesquisa. 0 objeto de pesquisa deve constituir-se efetivamente num fato social, e, como tal, deverá ser tratado como uma coisa. 0 nosso objeto ou o fenômeno pesquisado deverá apresentar as características de exterioridade, coercitividade e generalidade, próprias de um fato social. Caso contrário, corre-se o risco de se pesquisar algo que não se constitui em objeto de estudo científico.

Passemos então às três implicações apontadas por Durkheim, como decorrentes do fato social ser uma coisa:

1- "É necessário afastar sistematicamente todas as noções prévias" (DURKHEIM, 1973, p. 404). Portanto, na definição do objeto de pesquisa e durante a pesquisa, o pesquisador

2 - Apresento apenas a primeira regra, interpretada na perspectiva da realização da pesquisa que adotar a abordagem positivista deverá afastar-se dos preconceitos e prejuízos do senso comum e adotar uma postura científica, ou seja, procurar ser objetivo não se deixando levar por motivos subjetivos.

2- "Tomar sempre para objeto de investigação um grupo de fenômenos previamente definidos por certas características exteriores que lhes sejam comuns, e incluir na mesma investigação todos os que correspondam a esta definição". (DURKHEIM, 1973, p. 406). 0 pesquisador positivista deverá inicialmente definir o seu objeto de pesquisa, o fato a ser pesquisado. Mas tal definição não será feita com base num ideal que possua acerca do fenômeno pesquisado, nem com a pretensão de atingir logo de início a sua essência, e sim, a partir da observação do fato, captando as propriedades concretas que lhes são exteriores e que são da própria natureza do fenômeno. 0 pesquisador positivista deve partir, portanto, da sensação, da experiência sensorial, e não dos conceitos.

3- "Quando, o sociólogo empreende a exploração de uma qualquer ordem de fatos sociais, deve esforçar-se por considerá-los sob um ângulo em que eles se apresentem isolados das suas manifestações individuais". (DURKHEIM, 1973, p. 411). 0 pesquisador que adota o método positivista tende à objetividade dos fatos. Portanto, na sua pesquisa, quanto mais se afastar dos atos individuais, particulares, manifestos no fenômeno que estuda, mais objetividade obterá. Por isso, o pesquisador positivista prioriza, no seu procedimento de pesquisa, o que é padrão, constante, fixo, que não muda de acordo com as particularidades e individualidades.

Podemos sinteticamente concluir 0 seguinte acerca da pesquisa que se proponha numa abordagem positivista: o seu objeto, seja ele qual for, deverá ser estudado como uma "coisa", ou seja, deverá ser isolado do seu contexto, para que possa ser medido, mensurado, analisado, descrito. 0 pesquisador positivista captará o seu objeto a partir das suas características externas, descrevendo o que ele 
é de forma objetiva e neutra. E ao fazer isso, o pesquisador positivista conservará o seu objeto e a si próprio, pois buscará a identidade das coisas sem as suas contradições internas.

\section{O olhar de dentro}

0 olhar de quem está inserido, vivenciando um fenômeno; o olhar de dentro é o da fenomenologia. A postura fenomenológica e semelhante àquela do etnólogo: há que se vivenciar, estar presente, para se interpretar e compreender os fenômenos a partir dos sujeitos de processo, num determinado momento. A fenomenologia surge antepondo-se criticamente ao positivismo e ao psicologismo do final do século XIX e início do século XX. 0 principal nome da fenomenologia é o filósofo Edmund Husserl (1859-1938). A ele se atribui a criação da filosofia e do método fenomenológicos, muito embora o uso do termo fenomenologia e algumas de suas ideias já terem indícios ou precedentes na história da filosofia.

A intenção inicial de Husserl era tornar a filosofia uma ciência rigorosa que fosse a base segura, um conhecimento apodítico, para todas as ciências. Por isso, era necessário fazer a "redução fenomenológica", como veremos adiante, para atingir os fenômenos como eles se apresentam à consciência, ou seja, as essências (eidos). Para Husserl, o conhecimento começa com a experiência de coisas existentes, de fatos, de fenômenos que se apresentam à consciência. 0 fenômeno é "tudo aquilo que é vivência, na unidade de vivência de um eu" (HUSSERL, 1996, p. 207). Assim, tudo o que se apresenta à consciência é um fenômeno, um fato dado no aqui e agora para o sujeito que o vivencia. Contudo, quando a consciência intenciona um fenômeno contingente que a ela se apresenta, capta-se no fenômeno uma essência. Portanto, para o pensamento husserliano devemos superar a contraposição subjacente entre aparência e essência, onde o fenômeno é apenas a aparência da coisa em si.

Assim sendo, podemos compreender, por exemplo, que, ao escutar uma música, não escutamos uma aparência de música, mas a música, muito embora, essa música seja um fenômeno vivenciado no aqui e agora, seja contingente, nesse fenômeno, nossa consciência não capta só o que é aparente, ela capta também uma essência, de tal forma que identificamos o que escutamos como música, ou seja, intuímos o que ela é essencialmente e não apenas a sua particularidade. Por isso, Husserl define a fenomenologia como "a doutrina das vivências em geral, [...] a doutrina das essências" (HUSSERL, 1996, p. 207), cujo conhecimento das essências se dá pela intuição eidética, ou seja, nossa consciência capta, nos fatos particulares, as essências.

A fenomenologia não é ciência dos fatos, e sim ciência de essências. Para o fenomenólogo, não interessa a análise desta ou daquela norma moral, porém compreender por que esta ou aquela norma são normas morais e não, por exemplo, normas jurídicas ou regras de comportamento. Da mesma forma, o fenomenólogo não se interessará (ou, pelo menos, não se interessará principalmente) em examinar os ritos e os hinos desta ou daquela religião; ao contrário, ele se interessará por compreender o que é a religiosidade, ou seja, o que transforma ritos e hinos tão diferentes em ritos e hinos religiosos.

[...] Eis, portanto, o que a fenomenologia pretende ser: ciência, fundamentada estavelmente, voltada à análise e à descrição das essências. (REALE, 1991, p. 555).

É em Franz Bretano (1838-1917) que Husserl encontra a inspiração para o conceito central da fenomenologia: a intencionalidade. Para Bretano, a consciência sempre está direcionada para algo, é sempre consciência de alguma coisa. Husserl retoma esse conceito de intecionalidade da consciência. Para ele, a "consciência não é uma substância (alma), mas uma atividade constituída por atos (percepção, imaginação, especulação, volição, paixão etc.), 
com os quais visa algo". (CHAUÍ, 1996, p. 7). Os atos da consciência, o ter consciência, Husserl chamou de noesis; aquilo de que se tem consciência, o que é visado pelos atos da consciência, ele denominou noema. 0 conhecimento é o resultado da relação noesis e noema. Só conhecemos porque intencionamos algo que se nos manifesta e nos atrai. Nossa percepção (noesis) intenciona, visa a, um objeto percebido (noema). A consciência é então interessada, intencionada, interpretadora do mundo. Aqui temos uma implicação direta para a pesquisa. 0 fenomenólogo não age como o positivista, ante o seu objeto, ele não apenas o observa, ele age, intenciona, interessa-se, possui uma percepção própria do objeto:

\begin{abstract}
A fenomenologia exalta a interpretação do mundo que surge intencionalmente à nossa consciência. Por isso, na pesquisa, eleva o ator, com suas percepções dos fenômenos, sobre o observador positivista.

Os positivistas reificaram o conhecimento, transformaram-no num mundo objetivo, de “coisas". A fenomenologia, com sua ênfase no ator, na experiência pura do sujeito, realizou a desreificação do conhecimento, mas a nível da consciência, em sua forma subjetiva. (TRIVIÑOS, 1987, p. 47).
\end{abstract}

Duas outras categorias devem ser apreciadas para que possamos compreender o método fenomenológico. A primeira delas é o conceito de epoché ou redução fenomenológica; a segunda, a noção de intersubjetividade. Ambas as categorias estão diretamente relacionadas com a preocupação fundamental de Husserl em chegar a um conhecimento apodítico.

$\mathrm{Na}$ intencionalidade da consciência de captar o objeto, como garantir que o objeto ao manifestar-se fenomenicamente, seja apreendido essencialmente na sua pureza? Será necessário voltar às "coisas mesmas", pôr o mundo entre parênteses, ou seja, suspender as certezas, as verdades estabelecidas, os conhecimentos e juízos prévios acerca do objeto. E essa atitude crítica de suspensão da realidade Husserl denomina epoché, redução fenomenológica ou eidética. Não se trata de negação do mundo ou de ceticismo. A questão posta é se nos é possível compreender o sentido das coisas, dos fatos. A eidos (idéia ou essência) não deve ser compreendida do ponto de vista fenomenológico como um simples produto da mente, mas sim como o sentido que se intui nos fenômenos:

\begin{abstract}
Husserl afirma que para o ser humano é muito importante compreender o sentido das coisas, mas nem todas as coisas são imediatamente compreensíveis. Como o que interessa é o sentido das coisas, deixamos de lado tudo aquilo que não é o sentido do que queremos compreender e buscamos, principalmente, o sentido. Husserl diz, por exemplo, que não interessa o fato de existir, mas o sentido desse fato. Este é um ponto importante: existem os fatos? Certamente, existem. Mas não nos interessa os fatos enquanto fatos, interessamo-nos pelo sentido deles. Por isso posso também "colocar entre parênteses" a existência dos fatos para compreender sua essência. (BELLO, 2006, p.23).
\end{abstract}

De tal forma, o primeiro passo no método fenomenológico é a busca do sentido dos fenômenos, por meio da redução eidética. 0 fenomenólogo, ao pesquisar um dado fenômeno, aproxima-se da "coisa mesma" e não o faz a partir do que já está dito sobre o fenômeno pelas doutrinas filosóficas, científicas ou pelo conhecimento vulgar. A partir da epoché, ele aproxima-se do objeto de pesquisa sem dizer o que ele é, mas buscando compreendê-lo pelo que se manifesta. Mais do que explicação e análise, o que o fenomenólogo intenciona é a compreensão do que se apresenta à sua consciência.

Outra questão que se coloca para Husserl, e que terá implicação para o método fenomenológico, é que a produção do conhecimento na perspectiva fenomenológica dá-se a partir da vivência do sujeito. No 
entanto, a vivência é singular e subjetiva. Como então podemos obter um conhecimento apodítico, partindo da vivência? Não cairia a fenomenologia num solipsismo? A resposta de Husserl será a noção de intersubjetividade. Para ele, a fenomenologia é conhecimento das essências e essas são universais. Uma vez que o sujeito realizou a epoché, o que ele vivencia é a essência do fenômeno. Portanto, o que é universal e válido para todos os sujeitos: "0 mundo que eu conheço - diz Husserl - é o mundo que pode ser conhecido por todos" (TRIVINÕS, 1987, p. 46). Assim, a validade e a universalidade do conhecimento são garantidas pela intersubjetividade. Transportando para o campo da pesquisa, dizemos que a verdade do fenômeno não é a minha interpretação individual, subjetiva e isolada enquanto pesquisador, ela é apenas uma percepção, uma perspectiva, que iluminará junto com outras perspectivas de outros sujeitos, outros pesquisadores, o fenômeno estudado.

Podemos sinteticamente concluir o seguinte acerca da pesquisa que se proponha numa abordagem fenomenológica: o objeto de pesquisa é visto como um fenômeno que se manifesta à consciência do pesquisador. Este, por sua vez, intenciona o fenômeno, sente-se atraído por ele e, por vivenciá-lo numa determinada situação, busca compreendê-lo. Mas, para compreendê-lo o pesquisador deverá inicialmente fazer a epoché, ou seja, deverá questionar tudo o que sabe sobre o fenômeno, pôr entre parênteses os seus juízos e conhecimentos, sejam eles de que ordem for (crenças, preconceitos, teorias, explicações etc.).

0 fenomenólogo compreenderá também que o fenômeno que estuda não é uma "coisa", mas envolve a vivência humana daqueles que estão implicados no fenômeno. Portanto, o pesquisador buscará a vivência, a experiência dos sujeitos que vivenciam o fenômeno numa situação real. 0 pesquisador que vivencia o fenômeno de alguma forma sabe que a sua descrição do fenômeno não é suficiente para compreendê-lo. Portanto, pela intersubjetividade, nos discursos, nas descrições dos outros sujeitos, ele capta a essência do fenômeno. 0 pesquisador sabe que é um intérprete. E, também buscando compreender a descrição desses sujeitos, o pesquisador fará a epoché, que identificará a consistência dos discursos, depurando-os do que é secundário e manifestando o que é essencial, através das convergências dos discursos. Chega, assim, a uma generalização, não mais a uma descrição individual do fenômeno. Essa generalização contribuirá, junto com outras de outros pesquisadores, para compreender o fenômeno em sua inteireza.

\section{O olhar por baixo}

0 olhar por baixo ou por trás, aquele que busca captar o que dá sustentação, o que alicerça os fenômenos sociais, independente dos seus condicionamentos históricos, ou seja, a estrutura. Esse é olhar do estruturalismo. Surgido no início do século XX, o estruturalismo tem em Ferdinand de Saussure (1857-1913), na linguística, e Claude Lévi-Strauss (1908-2009), na antropologia, seus maiores formuladores. 0 estruturalismo é, no entanto, um complexo teórico muito abrangente e diversificado que perpassa além da linguística e da antropologia, a filosofia, a história, a psicologia, a sociologia. Em termos educacionais ,o estruturalismo teve forte influência da sociologia de Pierre Bourdieu e especialmente do construtivismo advindo de Jean Piaget.

Do ponto de vista filosófico, o estruturalismo representa uma reação ao existencialismo. Esse último, na esteira do método fenomenológico, acentuava a individualidade e a autonomia do sujeito, do "eu", como um ser livre e autor da sua história. Os estruturalistas, ao contrário, observaram que esse eu-sujeito-indivíduo livre não existe senão determinado por estruturas.

Ferdinand de Saussure já havia demonstrado, no estudo da linguística, que a língua não é formada por vocábulos e sim por estruturas fonéticas. Demonstração semelhante fez Lévi-Strauss ao estudar as relações de parentesco, em que apresenta pela primeira vez a abordagem estruturalista. 
No estudo das relações de parentesco [...], o sociólogo se encontra em situação formalmente semelhante à do lingüista fonólogo: como os fonemas, os termos de parentesco são elementos de significado; eles também só adquirem tal significado na condição de integrarem-se em sistema; os "sistemas de parentesco", assim como os "sistemas fonológicos", são elaborados pelo intelecto no estágio do pensamento inconsciente; por fim, a ocorrência, em regiões do mundo distantes entre si e em sociedades profundamente diferentes, de formas de parentesco, regras de matrimônio, comportamentos igualmente prescritos entre certos tipos de parentes etc., leva a crer que, em ambos os casos, os fenômenos observáveis decorrem de leis gerais, mas ocultas. (LÉVI-STRAUSS, apud REALE, 1991, p. 945)

Assim sendo, os fenômenos observáveis decorrem de leis gerais e ocultas, ou seja, os fenômenos humanos estudados obedecem a determinadas estruturas ou sistemas não perceptíveis, pois inconscientes. A atitude estruturalista prioriza e observa a primazia do todo (estrutura) sobre a parte (indivíduo), do estrutural sobre o pessoal e conjectural. Para os estruturalistas, não é a parte que explica o todo, mas o todo que explica a parte. 0 próprio termo estruturalismo evoca a explicação da realidade a partir de estruturas. Os estruturalistas buscam conhecer a realidade, desvendando as suas estruturas supratemporal e supra-espacial. Os fenômenos estão estruturados internamente e, ao mesmo tempo, são estruturantes da realidade como um todo:

A estrutura é própria de todos os fenômenos, coisas, objetos e sistemas que existem na realidade. É uma forma interior que caracteriza a existência do objeto. Ela preserva a unidade que peculiariza a coisa através das conexões estáveis que se estabelecem entre os diferentes elementos que a constituem. [...] 0 sistema social apresenta diferentes tipos de estruturas: social, econômica, educacional etc. Cada estrutura pode ser estudada separadamente. [...] 0 estruturalismo é uma abordagem científica que pretende descobrir a estrutura do fenômeno, penetrar em sua essência para determinar as suas ligações determinantes. (TRIVIÑOS, 1987, p. 80-81).

A partir dessas considerações, podemos aprofundar um pouco mais a compreensão do estruturalismo, vislumbrando as suas categorias principais. Primeiramente, vale salientar que, para o estruturalismo, as estruturas são estáveis, mas não permanentes. Portanto, existe o movimento e a variação na estrutura. A estrutura possui elementos estruturadores, que formam a sua base de sustentação, mas também possui elementos estruturantes, que são fatores de variação na estrutura. Dentro da estrutura, existem relações. 0 que determina a variação da estrutura não são as contradições internas - não aceitas como categoria de análise pelo estruturalismo -, mas sim as relações que são estabelecidas dentro da própria estrutura. As relações determinam a forma da sociedade e dos grupos sociais se estruturarem. Mudandose as relações internas, surge outra estrutura. Portanto, compreender uma estrutura é também compreender as relações internas que ocorrem nessa estrutura. As realidades estruturadas, as estruturas, devem ser analisadas em si mesmas, pois possuem uma lógica interna própria.

É justamente essa lógica interna própria que o pesquisador estruturalista quer captar, ou seja, o que é estável na mudança, na variação, pois aí é que se encontra a essência da estrutura do real pesquisado, a invariante. Assim como Lévi-Strauss demonstrou, ao estudar vários mitos, que, para além das suas variações temporais e espaciais, existiam elementos comuns constituintes, estruturadores, definidores do mito enquanto tal, também o pesquisador estruturalista investirá esforço no sentido de encontrar o que é invariável no seu objeto de estudo. A categoria das invariantes é fundamental para o estruturalista esclarecer a realidade: 
Podemos afirmar que o estruturalismo apresenta metodologicamente a seguinte perspectiva: só explicamos a variação, quando descobrimos como ela invariavelmente varia. Toda variação como fenômeno estruturado que é, apresenta modos constantes de variar. Nestes modos constantes de variar está, ao mesmo tempo, sua natureza mais profunda e sua explicação. Por outra: a manifestação variável é secundária e menos explicativa. (DEMO, 1995, p. 178, grifo do autor).

Como existem as invariantes que são constantes supratemporais e supra-espaciais, o estruturalismo não prioriza o estudo histórico como fundamental para a explicação dos fenômenos. A história tem um papel secundário e derivado, pois os acontecimentos não são explicados senão dentro de uma estruturação do real. Assim, não tem sentido estudar com primazia o desenrolar histórico de um fenômeno; o que se deve buscar é o invariante que o explica, independente de tempo e lugar. A estrutura é explicada a partir dela mesma e não a partir da história. Por outro lado, a história é explicada a partir da estrutura.

Podemos sinteticamente concluir o seguinte acerca da pesquisa que se proponha numa abordagem estruturalista: o seu objeto de estudo é tomado como uma estrutura. 0 pesquisador buscará captar os elementos estruturadores e estruturantes do seu objeto. Tal estudo do objeto não será feito de uma perspectiva histórica, mas a partir de uma análise interna, em que o pesquisador estruturalista observará as relações que aí ocorrem e se estabelecem, percebendo quais são as variações ocorridas e identificando o que não varia, o invariante que explica a estrutura estudada.

\section{O olhar multidimensional}

O olhar complexo ou multidimensional nasce no seio da crise paradigmática da ciência moderna. É um olhar que não se satisfaz com a fragmentação disciplinar da ciência, nem com a sua pretensão de verdade única e universal. Edgar Morin (1921-) é o principal teórico do pensamento complexo. Morin denomina o paradigma científico da modernidade de paradigma simplificador, ao qual contrapõe o paradigma da complexidade. Para ele "os modos simplificadores de conhecimento mutilam mais do que exprimem as realidades ou os fenômenos de que tratam, e torna-se evidente que eles produzem mais cegueira do que elucidação" (MORIN, 2006, p. 5).

Trata-se de uma patologia do saber, a inteligência cega, que impôs os princípios de disjunção, de redução e de abstração, constitutivos do paradigma simplificador. Tal paradigma foi formulado e legado ao Ocidente por Descartes, “ao separar o sujeito pensante (ego cogitans) e a coisa entendida (res extensa), isto é, filosofia e ciência, e ao colocar como princípio de verdade as ideias claras e distintas, isto é, o próprio pensamento disjuntivo" (MORIN, 2006, p.11).

Para Morin (2010), existe uma ambivalência, o lado bom e o lado mau da ciência, a complexidade intrínseca no cerne da ciência. A ciência é elucidativa, enriquecedora, conquistadora, triunfante e, ao mesmo tempo, um problema, com possibilidades de subjugação e aniquilamento. 0 pensamento complexo é capaz de compreender tal ambivalência e romper com o pensamento simplificador e disjuntivo. Mas é necessário desfazer duas ilusões quanto à complexidade: acreditar que conduza à eliminação da simplicidade (ao contrário, a complexidade integra em si tudo o que põe ordem, clareza, distinção, precisão no conhecimento); confundir complexidade e completude (o pensamento complexo aspira ao conhecimento multidimensional). 0 que o olhar multidimensional do paradigma da complexidade intenciona é romper com a fragmentação, a mutilação, a separação e a redução que o olhar unidemensional do paradigma simplificador lança sobre a realidade natural e social. Na sua pretensão de verdade, 
clareza e distinção, o pensamento simplificador estabelece dicotomias e fragmentações: homem/natureza; sujeito/objeto; psíquico/ físico; cultural/biológico etc.

De acordo com Morin (2010, p. 177), “ao aspirar a multidimensionalidade, o pensamento complexo comporta em seu interior um princípio de incompletude e de incerteza”. 0 que constitui motivo de inspiração, motivação e criação para o sujeito do conhecimento, longe de ser um princípio de impossibilidade para a produção do conhecimento científico segundo a lógica do pensamento simplificador. $\mathrm{Na}$ sua complexidade, a realidade e o conhecimento compreendem ao mesmo tempo a inseparabilidade da ordem e da desordem, a certeza da incerteza, o previsível do acaso, a parte do todo, o observador do observado, o racional do irracional, o uno do múltiplo (unitas multiplex). Morin (2010, p. 192) afırma que "a complexidade é isso: a junção de conceitos que lutam entre si”. 0 pensamento complexo busca reunir, religar os saberes a fim de poder captar o tecido da complexidade. "Complexus é o que está junto; é o tecido formado por diferentes fios que se transformaram numa só coisa" (2010, p. 188). Tudo se entrecruza e se entrelaça formando a unidade do complexus; mas esta não destrói a variedade e a diversidade das complexidades que o teceram.

Morin estabelece três princípios imbricados, orientadores da complexidade:

a) Princípio hologramático - "Holograma é a imagem física cujas qualidades de relevo, de cor e de presença são devidas ao fato de cada um dos seus pontos incluírem quase toda a informação do conjunto que ele representa" (MORIN, 2010, p. 181). Pelo princípio hologramático, compreende-se que não só a parte está no todo, como também o todo está na parte. A complexidade rejeita ao mesmo tempo o reducionismo de querer compreender o todo partindo só das partes e o holismo que quer compreender o todo negligenciando as partes.

b) Princípio da organização recursiva “A organização recursiva é a organização cujos efeitos e produtos são necessários a sua própria causação e a sua própria produção" (MORIN, 2010, p. 182). A organização recursiva rompe com a linearidade do pensamento causal, trazendo a ideia da recursividade do produto sobre o produtor. Assim, a complexidade não é só um fenômeno empírico marcado intrinsecamente pela "mistura dos fenômenos", as inter-relações e as imprevisibilidades, mas “é, também, um problema conceitual e lógico que confunde as demarcações e as fronteiras bem nítidas dos conceitos como 'produtor' e 'produto', 'causa' e 'efeito', 'um' e 'múltiplo’” (MORIN, 2010, p. 183).

c) Princípio dialógico - "0 termo dialógico quer dizer que duas lógicas, dois princípios, estão unidos sem que a dualidade se perca nessa unidade: daí vem a ideia de 'unidualidade' [...]" (MORIN, 2010, p. 189). Pelo princípio dialógico, é possível estabelecer relação entre aspectos antagônicos e ao mesmo tempo complementares, sem negar ou reduzir a complexidade desta relação.

Podemos sinteticamente concluir o seguinte acerca da pesquisa que se proponha numa abordagem complexa: ao adotar um olhar multidimensional, o pesquisador não isolará ou fragmentará o objeto; ao contrário, buscará compreendê-lo no tecido complexus da realidade. Também não terá a pretensão do entendimento ou da elucidação absoluta do objeto de pesquisa; ao contrário, deverá considerar a incerteza, a incompletude, o acaso, a ambivalência, como elementos constitutivos e motivadores da pesquisa. Seu olhar complexo, multidimensional, fará o pesquisador estabelecer relações entre as diversas áreas do saber e adotar uma perspectiva inter e transdisciplinar na investigação. Assim, não fará disjunção entre fenômenos biológicos e culturais; também não olhará apenas sob a perspectiva das ciências humanas ou das ciências naturais; e também não fará segregação entre qualitativo e quantitativo.

Adotando os princípios hologramático, da organização recursiva e dialógico, o pesquisador 
complexo compreenderá: que ele e o objeto são partes de um todo e que nele e no objeto também está o todo; que ele produz o objeto, mas que este também o produz; que ele dialoga com o objeto, que dialoga com o mundo, que dialoga com outros sujeitos, que também dialogam com o objeto e com o mundo. Ou seja, por um lado, o pesquisador compreende que existem conexões, redes, teias de significados, uma complexidade na pesquisa que faz com que a produção do conhecimento seja sistêmica. Por outro lado, assume uma regra de complexidade: "o observador-conceptor deve se integrar na sua observação e na sua concepção" (MORIN, 2010, p. 185).

\section{Considerações finais}

Após essa visão panorâmica de algumas das principais epistemologias, vale considerar a importância da teoria e do referencial metodológico na pesquisa científica em educação. Todas as epistemologias, a partir de categorias diversas, propõem-se a explicar a realidade. Com as epistemologias, temos os elementos teóricos, por assim dizer, de fundo, que nos fornecem os fundamentos e a chave de leitura para a realidade. Cada epistemologia, enquanto teoria que se constitui, oferece uma possibilidade de leitura de mundo, uma visão da realidade, e, ao mesmo tempo, esclarece como metodologicamente se produz o conhecimento desse mundo, como é possivel conhecermos a realidade.

Uma metodologia vincula-se a uma teoria/epistemologia. Toda teoria/epistemologia tem seus limites, não consegue apreender e explicitar tudo do real, pelo simples fato de nós, seres humanos, sermos também limitados. Não somos oniscientes. No entanto, sem uma teoria, não é possível o senso crítico da realidade. A teoria explica a realidade, enquanto produz uma metodologia que torna possível a aproximação da realidade pesquisada. No caso de cada área específica de formação (como as licenciaturas), no processo de elaboração de um determinado estudo ou pesquisa e no trato, na abordagem, que faz do seu objeto, tem-se uma leitura de mundo, uma compreensão subjacente da realidade, que vincula aquele estudo específico a uma ou mais epistemologias. Nesse sentido, a pluralidade de epistemologias na pesquisa em educação, longe de ser interpretada como um “obstáculo epistemológico ou obstáculo pedagógico" (BACHELHARD, 1996) para a compreensão dos fenômenos educacionais, deve ser vista como um fator de enriquecimento epistemológico: “A presença de várias opções epistemológicas na produção científica em educação enriquece a dinâmica da produção, permite uma melhor definição metodológica e uma maior profundidade na reflexão sobre a problemática educativa" (GAMBOA, 2012, p. 104).

As epistemologias aqui apresentadas são vistas como possibilidades de olhares diversos sobre os fenômenos educacionais; ora convergentes, ora divergentes, completando-se ou excluindo-se. 0 que um olhar epistemológico enxerga outro pode não enxergar. Nessa ótica da pesquisa educacional, estaremos numa dinâmica constante entre visão e/ou cegueira, a possibilidade de lucidez e/ou obscuridade. Como diz Bachelard (1996, p. 17), "O conhecimento do real é luz que sempre projeta algumas sombras. Nunca é imediato e pleno".

Por fim, é oportuno considerar que o processo de produção do conhecimento, em qualquer área que ocorra, não é neutro: ou contribui para a manutenção e conservação da realidade ou contribui para mudar e transformar a realidade. Fazer pesquisa em educação e definir uma metodologia de investigação educacional não é apenas definir um rol de procedimentos práticos e experimentais, mas envolve mudança de olhar, o que tem implicações no direcionamento político e pedagógico da docência. Não considerar esse aspecto é já por si só posicionar-se por uma atitude não crítica, baseada numa pretensa neutralidade científica.

Vale dizer que não é a teoria em si que transforma o real. A teoria sem dúvida já é uma ação, é um fazer. Mas uma ação e um fazer do pensamento, à maneira do pensamento, ou seja, uma abstração que nos leva a construir 
mentalmente, a explicar, a organizar, a compreender, a nos situar no mundo, a criticar ou a justificar uma realidade. Por isso, a sua importância e vínculo com a ação, com a prática, com o fazer, que, por sua vez, não são esclarecidos e evidentes por si mesmos, mas carecem de um aporte teórico que os tornem inteligíveis. Existe uma estreita relação entre o agir e o pensar; a prática e a teoria não estão dissociados. 0 que pode ocorrer é uma não consciência, uma inconsciência ou uma má consciência dessa relação. 0 que revela mais uma vez a necessidade da epistemologia na formação do professor pesquisador.

\section{Referências}

BACHELARD, Gaston. A formação do espírito científico: contribuição para uma psicanálise do conhecimento. Rio de Janeiro: Contraponto, 1996.

BELLO, Angela Ales. Introdução à fenomenologia. Bauru: Edusc, 2006. (Filosofia e política).

CAVALCANTI, Alberes de Siqueira; BRUSSIO, Josenildo Campos; TOURINHO, Mary Angélica. Alguns olhares sobre a crise da modernidade. In: VASCONCELOS, José Gerardo; SOUSA, Antonio Paulino (Org.). Educação, política e modernidade. Fortaleza: UFC, 2006. p. 79-93. (Diálogos intempestivos, 40).

CAVALCANTI, Alberes de Siqueira; SILVA, Maria de Fátima Vilhena da; MACÊDO, Francisco Cristiano da Silva. Bases epistemológicas em educação em ciências: imagens da ciência e o processo de ensino-aprendizagem. In: CONFERENCIA DE LA ASOCIACIÓN LATINO AMERICANA DE INVESTIGACIÓN EN EDUCACIÓN EN CIENCIAS, LASERA. Anais, Manaus, 2013.

CHAUÍ, Marilena. Vida e obra. In: HUSSERL, Edmund. Investigações lógicas: elementos de uma elucidação fenomenológica do conhecimento. São Paulo: Nova Cultural, 1996. (Os pensadores).

COMTE, Auguste. Discurso sobre o espírito positivo. São Paulo: Abril, 1973. (Os pensadores).

DEMO, Pedro. Metodologia científica em ciências sociais. 3. ed. São Paulo: Atlas, 1995.

DURKHEIM, Émile. As regras do método sociológico. São Paulo: Abril, 1973. (Os pensadores).

GAMBOA, Silvio Sánchez. Pesquisa em educação: métodos e epistemologias. 2. ed. Chapecó/SC: Argos, 2012.

HUSSERL, Edmund. Investigações lógicas: elementos de uma elucidação fenomenológica do conhecimento. São Paulo: Nova Cultural, 1996. (Os pensadores).

KOSIK, Karel. Dialética do concreto. 2. ed. Rio de Janeiro: Paz e Terra, 1976.

LEFEBVRE, Henri. Lógica formal lógica dialética. 2. ed. Rio de Janeiro: Civilização Brasileira, 1979.

MARX, Karl. Para a crítica da economia política. São Paulo: Nova Cultural, 1999. (Os pensadores).

MEYER, Philippe. 0 olho e o cérebro: biofilosofia da percepção visual. São Paulo: UNESP, 2002.

MORIN, Edgar. Introdução ao pensamento complexo. Porto Alegre: Sulina, 2006.

MORIN, Edgar. Ciência com consciência. 13. ed. Rio de Janeiro: Bertrand Brasil, 2010.

PORLÁN, Ariza; GARCÍA, Rivero; POZO, Martin del. Conocimiento professional y epistemología de los profesores: estudios empíricos y conclusiones. Enseñanza de las Ciencias, v. 16, n. 2, p. 271-288, 1998.

PRAIA, João; CACHAPUZ, Antonio; GIL-PÉREZ, Daniel. Problema, teoria e observação em ciência: para uma reorientação epistemológica da educação em ciência. Ciência \& Educação, v. 8, n. 1, p.127-145, 2002.

REALE, Giovanni; ANTISERI, Dario. História da filosofia: do Romantismo até nossos dias. 3. ed. São Paulo: Paulus, 1991.

TRIVIÑOS, Augusto Nibaldo Silva. Introdução à pesquisa em ciências sociais: a pesquisa qualitativa em educação. São Paulo: Atlas, 1987.

Recebido em: 12.06.2013

Aprovado em: 11.12.2013

Alberes de Siqueira Cavalcanti é doutorando em Educação em Ciências pelo Programa de Doutorado em Educação em Ciências e Matemática (REAMEC), Polo UFPA, mestre em Educação pela UFMA e professor de Filosofia do Instituto Federal de Educação, Ciência e Tecnologia do Maranhão (IFMA), Campus São Luís Monte Castelo. 